\title{
Percutaneous Microcoil Localization of a Small, Totally Endophytic Renal Mass for Nephron-Sparing Surgery: A Case Report and Literature Review
}

\section{Tianhao Su}

Capital Medical University Affiliated Beijing Friendship Hospital

\section{Zhiyuan Zhang}

Capital Medical University Affiliated Beijing Friendship Hospital

\section{Meishan Zhao}

Capital Medical University Affiliated Beijing Friendship Hospital

\section{Gangyue Hao}

Capital Medical University Affiliated Beijing Friendship Hospital

\section{Ye Tian}

Capital Medical University Affiliated Beijing Friendship Hospital

Long Jin ( $\nabla$ longerg@hotmail.com )

https://orcid.org/0000-0003-1361-6173

\section{Case report}

Keywords: Microcoil, Preoperative localization, Partial nephrectomy, Endophytic renal mass, Computed tomography

Posted Date: May 12th, 2021

DOl: https://doi.org/10.21203/rs.3.rs-488832/v1

License: (c) (i) This work is licensed under a Creative Commons Attribution 4.0 International License. Read Full License 


\section{Abstract}

Background: Small, totally endophytic renal masses present a technical challenge for surgical extirpation due to poor identifiability during surgery. The method for the precise localization of totally endophytic tumours before nephron-sparing surgery could be optimized.

Case presentation: An asymptomatic 70-year-old male presented with a right-sided, 16-mm, totally endophytic renal mass on computed tomography (CT). CT-guided percutaneous microcoil localization was carried out prior to laparoscopy to provide a direction for partial nephrectomy. During the 25 minutes of the localization procedure, the patient underwent five local CT scans, and his cumulative effective radiation dosage was $5.1 \mathrm{mSv}$. The span between localization and the start of the operation was 15 hours. The laparoscopic operation time was 105 minutes, and the ischaemia time was 25 minutes. The postoperative recovery was smooth, and no perioperative complications occurred. Pathology showed the mass to be renal clear cell carcinoma, WHO/ISUP grade 2, with a 2-mm, clear surgical margin. The patient remained free of recurrence on follow-up for eleven months. To our knowledge, this application of microcoil implantation prior to laparoscopic partial nephrectomy for an intrarenal mass could be the first reported localized method applied in renal surgery.

Conclusions: The percutaneous microcoil localization of endophytic renal tumours is potentially safe and effective prior to laparoscopic partial nephrectomy.

\section{Introduction:}

Small, totally endophytic renal masses present a technical challenge for surgical extirpation due to poor identifiability during surgery. There are dozens of technology-enhanced methods for tumour localization in several surgical specialities [1-5]. However, the method for the precise localization of totally endophytic tumours before nephron-sparing surgery could be optimized. We report the application of percutaneous microcoil localization in a case of a small, totally endophytic renal mass prior to nephronsparing surgery.

\section{Case Presentation:}

A 70-year-old male was referred to our hospital in June 2020 because of a right renal mass accidentally detected on computed tomography (CT). There were no complaints of haematuria, abdominal masses, pain, or weight loss. The patient's past medical history included hypertension, coronary artery disease, and chronic hepatitis B. His medications included olmesartan, aspirin and entecavir. There was no family history of cancer, and the physical examination was unremarkable.

Abdominal contrast-enhanced CT revealed a round-like mass with obvious early enhancement in the middle part of the right kidney. The mass did not protrude beyond the renal contour and was accompanied by slight shrinkage of the renal cortex (Fig. 1A-E). 
In preoperative discussion, urologists did not believe that the small renal mass could be accurately identified or palpated during nephron-sparing surgery. Considering that the mass was located in the lateral region of the right kidney and intraoperative ultrasound (US) was highly dependent on the operator, we decided to perform microcoil implantation prior to laparoscopy to provide a direction for partial nephrectomy.

After preoperative evaluations were performed and informed consent was obtained, the patient underwent CT-guided localization of the small renal mass without any complications or obvious inconvenience. A tornado-like radio-opaque microcoil (MWCE-18S-6/2-TORNADO, Cook Medical, Bloomington, IN, USA) was implanted into the renal parenchyma targeting the small renal mass (Fig. 1F).

The right kidney was examined by CT five times, and the cumulative effective radiation dosage was 5.1 mSv. The span between CT-guided microcoil localization and the start of the operation was 15 hours. Under general anaesthesia, the patient underwent laparoscopic partial nephrectomy in the left lateral position. Laparoscopic exploration of the retroperitoneal cavity revealed the implanted microcoil protruding from the dorsal surface of the right kidney (Fig. 2A). The resection range was $2 \mathrm{~cm}$ in radius with the implanted microcoil as the centre. The mass was completely removed without excessive damage to the renal vasculature or collecting system (Fig. 2B). The operation time was 105 minutes, and the ischaemia time was 25 minutes.

The postoperative recovery was smooth, and no perioperative complications occurred. The postoperative serum creatinine concentration was $88.4 \mu \mathrm{mol} / \mathrm{L}$, within the normal range, and no hydronephrosis was observed on US at the postoperative follow-up. The final pathological result revealed T1a renal cell carcinoma (RCC), WHO/ISUP grade 2, $16 \mathrm{~mm}$ in greatest dimension. The tumour did not involve the perirenal capsule and was at least $2 \mathrm{~mm}$ away from the surgical margin. Eleven months later, follow-up magnetic resonance imaging showed no RCC recurrence, and the patient remained asymptomatic.

\section{Discussion:}

The incidence of RCC is rising in large part due to increased utilization of imaging [6]. Asymptomatic, localized T1a RCC $(\leq 4.0 \mathrm{~cm})$ constitutes the majority of new diagnoses [7]. Nephron-sparing approaches are the standard treatment for these patients. Regarding T1a RCC, endophytic tumours are centrally located and nearer to the collecting system [8]. Small, totally endophytic renal masses pose some difficulties in terms of laparoscopic nephron-sparing excision, especially in tumour identification and complete resection [2]. A small, totally endophytic renal mass cannot be accurately detected by conventional intraoperative observation or palpation. Although near-infrared fluorescence imaging has been considered transiently helpful in identifying the vascular anatomy, it is not helpful at all for endophytic tumours [3]. Additionally, intraoperative real-time localization has greater prospects for development; however, this method is not currently widely applied due to the high cost and prolonged operation time [5]. In addition, the preoperative superselective transarterial delivery of a lipidolindocyanine green (ICG) mixture to trace endophytic tumours has been described [3, 9], but related 
transarterial liquid diffusion and allergy must be taken into account. There has also been a case report on the application of hook-wire localization prior to laparoscopic partial nephrectomy for an intrarenal mass [4]; nevertheless, persistent pain is problematic.

We have previously described a modified microcoil method for the precise preoperative localization of pulmonary nodules before video-assisted thoracoscopic surgery, with satisfactory results [10]. We adopted a similar method in renal surgery to localize the renal mass. To our knowledge, this application of microcoil implantation prior to laparoscopic partial nephrectomy for an intrarenal mass could be the first reported localized method applied in renal surgery.

Our application provided the opportunity to avoid the use of intraoperative US or an alternative to US if it was not available. This method provides direct guidance in particularly tricky cases of endophytic tumours in which the surgeon requires confirmation of which strategy is best to achieve a safe operation for the patient.

There have been few published reports on the usefulness, efficacy and safety of the microcoil localization of tumours in nephron-sparing surgery. Evidence from video-assisted thoracic surgery suggests that microcoil localization is an effective and useful technique [11-14]. The patient in our report received an acceptable radiation dosage and experienced no discomfort. Microcoil localization could be a feasible and safe method that can be used preoperatively to provide enhanced insight into renal masses for urologists. Importantly, our method enables the tail of the microcoil to be easily placed outside the kidney surface. Consequently, the mass can be easily found during laparoscopy, reducing the time required for mass excision. The microcoil, which is usually used for blood vessel embolization, is preloaded and covered by synthetic fibres. These synthetic fibres are intended to activate coagulation and thus may also prevent puncture-related bleeding.

Notably, implantation of the microcoil does not need to be performed on the day of surgery, which is different from approaches using dyes or contrast agents. Concerning hook-wire localization, the introduction of the wire was carried out just before the surgery to minimize the potential risk of wire migration. Therefore, our preoperative localization method is more convenient than others and does not need special equipment or additional time on the day of surgery. After the microcoil was successfully implanted into the renal parenchyma towards the mass, urologists were able to observe the relationship between the microcoil and the endophytic mass on the subsequent CT scans, facilitating the following exploration during laparoscopy.

Although accurately identifying renal masses on CT without contrast perhaps is uneasy sometimes, we could recognize the target mass using CT plane information, for example, nearby blood vessels, bone markers, organs and tissues $\square$ As totally endophytic masses are not common among all resectable renal tumours, over the long term, this method could be applied in more cases with similar characteristics to gain more valuable and conclusive results. 


\section{Conclusions:}

We have reported our experience with the application of microcoil localization for an intrarenal mass. The percutaneous microcoil localization of endophytic renal tumours is potentially safe and effective prior to laparoscopic partial nephrectomy.

\section{Declarations:}

\section{Ethics approval and consent to participate}

The participant in our study provided signed informed consent. This study was reviewed and approved by the Clinical Research Ethics Committee of the Beijing Friendship Hospital, Capital Medical University,and the IRB is 2017-P1-038-01.

\section{Consent for publication}

We obtained the patient's consent for publication of this case report.

\section{Competing interests}

All the authors have no possible competing interests.

\section{Funding}

This study was supported by the Capital Health Research and Development of Special (No. Z191100006619030), the Capital Foundation of Medical Development (No. 2020-2Z-20212) and the "Sailing" Plans of Clinical Technology Innovation Project in 2018, Beijing Municipal Hospital Administration (XMLX201801).

\section{Authors' contributions}

\# TH Su and ZY Zhang contributed equally to this work; L Jin designed the research; GY Hao and Y Tian performed the surgery; TH Su, ZY Zhang and MS Zhao analyzed the data; TH Su and ZY Zhang wrote the paper. All authors read and approved the final manuscript.

\section{Acknowledgements:}

We would like to acknowledge the reviewers for their helpful comments on this paper.

\section{Availability of data and materials}

The datasets used or analysed during the presenting case are available from the corresponding author on reasonable request. 
The authors declare no conflicts of interests.

\section{References:}

1. Le O, Wood C, Vikram R, Patnana M, Bhosale P, Bassett R, Bedi D. Feasibility of Contrast-Enhanced Intraoperative Ultrasound for Detection and Characterization of Renal Mass Undergoing Open Partial Nephrectomy. J Ultrasound Med. 2017;36:1547-53.

2. Hekman MCH, Rijpkema M, Langenhuijsen JF, Boerman OC, Oosterwijk E, Mulders PFA. Intraoperative Imaging Techniques to Support Complete Tumor Resection in Partial Nephrectomy. Eur Urol Focus. 2018;4:960-8.

3. Simone G, Tuderti G, Anceschi U, Ferriero M, Costantini M, Minisola F, Vallati G, Pizzi G, Guaglianone S, Misuraca L, Gallucci M. "Ride the Green Light": Indocyanine Green-marked Off-clamp Robotic Partial Nephrectomy for Totally Endophytic Renal Masses. Eur Urol. 2019;75:1008-14.

4. Kouriefs C, Georgiades F, Michaelides M, loannides K, Kouriefs A, Grange P. Percutaneous hook wire assistance during laparoscopic excision of an intrarenal mass. Ann R Coll Surg Engl. 2019;101:e136-8.

5. Thammineedi SR, Saksena AR, Nusrath S, lyer RR, Shukla S, Patnaik SC, Reddy RP, Boleneni N, Sharma RM, Smith L, Are C. Fluorescence-guided cancer surgery-A new paradigm. J Surg Oncol 2021.

6. Lightfoot N, Conlon M, Kreiger N, Bissett R, Desai M, Warde P, Prichard HM. Impact of noninvasive imaging on increased incidental detection of renal cell carcinoma. Eur Urol. 2000;37:521-7.

7. Banegas MP, Harlan LC, Mann B, Yabroff KR: Toward greater adoption of minimally invasive and nephron-sparing surgical techniques for renal cell cancer in the United States. Urol Oncol 2016, 34:433.e439-433.e417.

8. Maciolek KA, Abel EJ, Posielski NM, Hinshaw JL, Lubner MG, Lee FT Jr, Ziemlewicz TJ, Wells SA. Tumor location does not impact oncologic outcomes for percutaneous microwave ablation of clinical T1a renal cell carcinoma. Eur Radiol. 2019;29:6319-29.

9. Diana P, Buffi NM, Lughezzani G, Dell'Oglio P, Mazzone E, Porter J, Mottrie A. The Role of Intraoperative Indocyanine Green in Robot-assisted Partial Nephrectomy: Results from a Large, Multiinstitutional Series. Eur Urol 2020.

10. Su TH, Fan YF, Jin L, He W, Hu LB. CT-guided localization of small pulmonary nodules using adjacent microcoil implantation prior to video-assisted thoracoscopic surgical resection. Eur Radiol. 2015;25:2627-33.

11. Park CH, Han K, Hur J, Lee SM, Lee JW, Hwang SH, Seo JS, Lee KH, Kwon W, Kim TH, Choi BW. Comparative Effectiveness and Safety of Preoperative Lung Localization for Pulmonary Nodules: A Systematic Review and Meta-analysis. Chest. 2017;151:316-28.

12. Mayo JR, Clifton JC, Powell TI, English JC, Evans KG, Yee J, McWilliams AM, Lam SC, Finley RJ. Lung nodules: CT-guided placement of microcoils to direct video-assisted thoracoscopic surgical 
resection. Radiology. 2009;250:576-85.

13. Finley RJ, Mayo JR, Grant K, Clifton JC, English J, Leo J, Lam S. Preoperative computed tomographyguided microcoil localization of small peripheral pulmonary nodules: a prospective randomized controlled trial. J Thorac Cardiovasc Surg. 2015;149:26-31.

14. Rodrigues JCL, Pierre AF, Hanneman K, Cabanero M, Kavanagh J, Waddell TK, Chung TB, Pakkal M, Keshavjee S, Cypel M, et al. CT-guided Microcoil Pulmonary Nodule Localization prior to Videoassisted Thoracoscopic Surgery: Diagnostic Utility and Recurrence-Free Survival. Radiology. 2019;291:214-22.

\section{Figures}
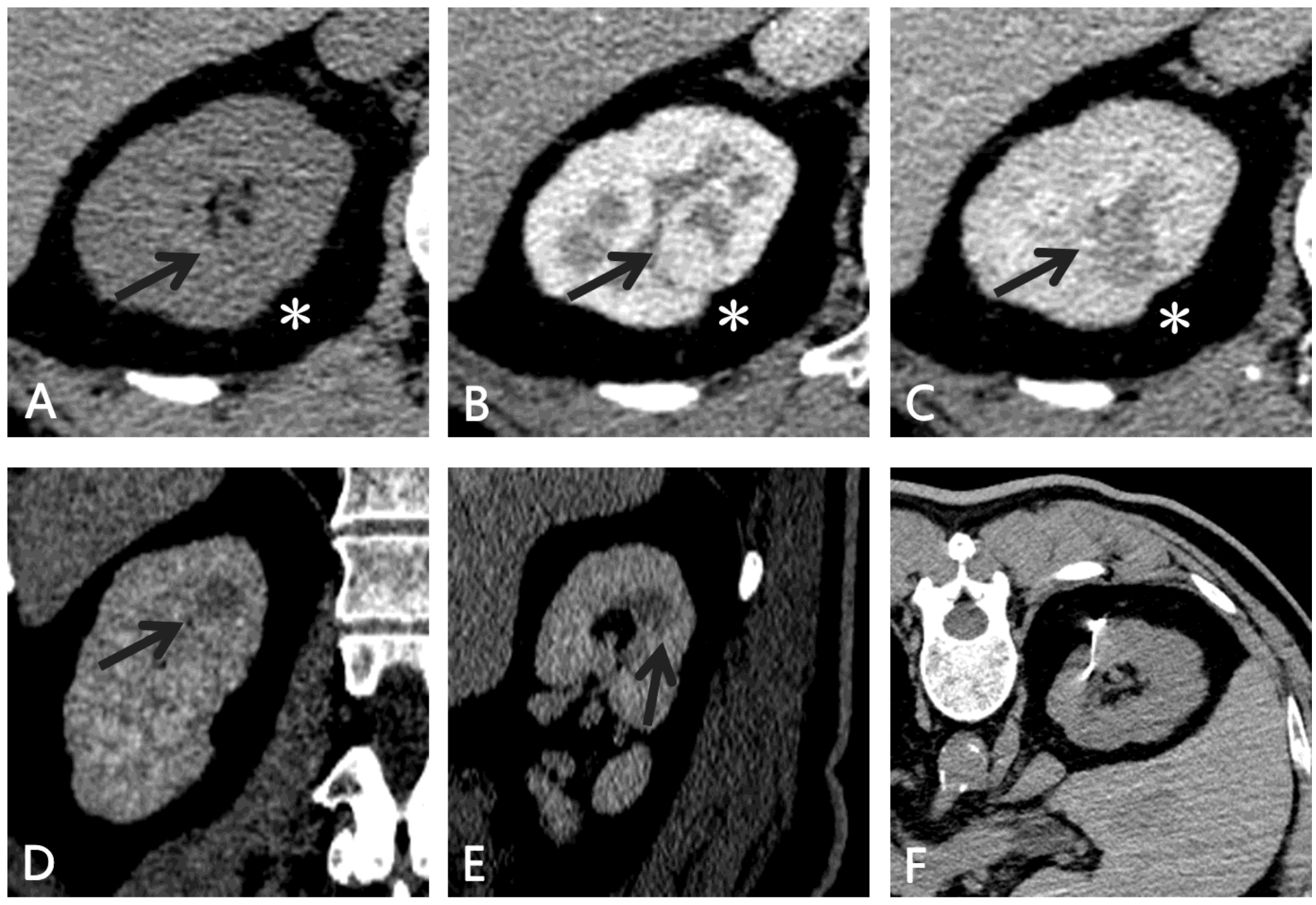

\section{Figure 1}

(A-C) An enhancing endophytic mass(black arrow) measuring $1.6 \times 1.4 \mathrm{~cm}$ was observed in the middle part of the right kidney. Slight shrinkage $\left(^{*}\right)$ was noted and taken as a puncture reference. During the excretory phase, the mass(black arrow) showed a different enhancement pattern (contrast washout) on 
coronal (D) and sagittal (E) views. (F) After the microcoil was implanted targeting the lesion, abdominal CT was performed to confirm the position of the microcoil and search for any complications.
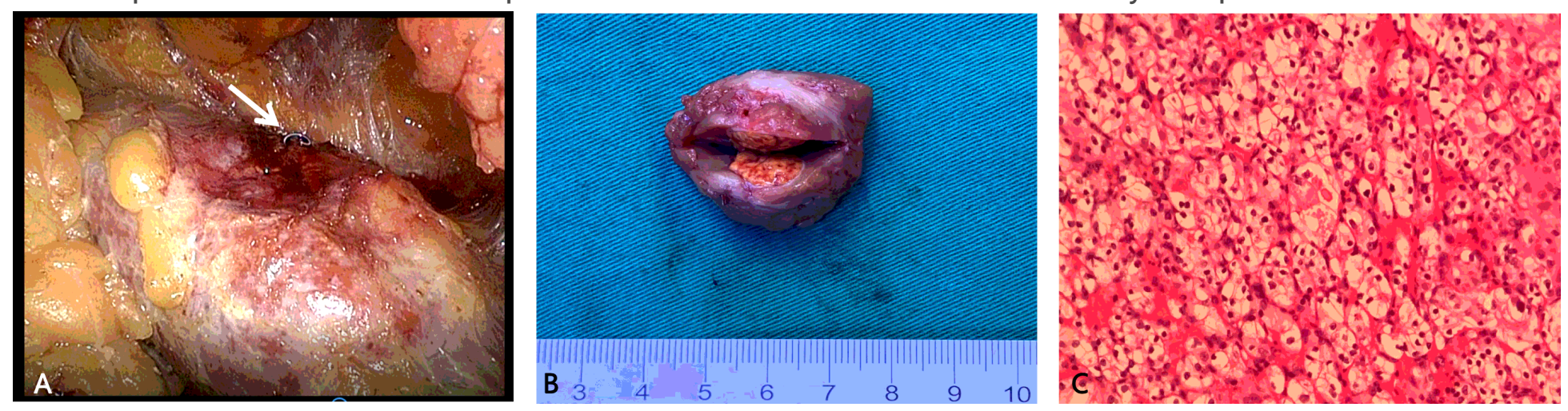

Figure 2

(A) The microcoil tail (white arrow) was visualized during laparoscopy. (B) The excised specimen after partial nephrectomy showed an intact tumour with a clear margin. (C) Microscopic sections of the mass showed large polygonal cells with clear cytoplasm and centrally placed small nuclei, indicating RCC (haematoxylin-eosin, original magnification 200x). 